\title{
Novos táxons de Cerambycinae (Coleoptera, Cerambycidae) da Região Neotropical
}

\author{
Ubirajara R. Martins ${ }^{1,3}$ \& Maria Helena M. Galileo ${ }^{2,3}$
}

1. Museu de Zoologia, Universidade de São Paulo, Caixa Postal 42494, 04218-970 São Paulo, SP, Brasil.

2. Museu de Ciências Naturais, Fundação Zoobotânica do Rio Grande do Sul, Caixa Postal 1188, 90001-970 Porto Alegre, RS, Brasil. 3. Bolsista do CNPq.

\begin{abstract}
New taxa of Cerambycinae (Coleoptera, Cerambycidae) of the Neotropical Region. The following new taxa are described and illustrated - in Oemini, Methioidina: Kalore gen. nov., type species K. asanga sp. nov.; in Methiini: Tessaropa boliviana sp. nov.; in Smodicini: Marupiara gen. nov., type species $M$. castanea sp. nov.; in Ectenessini: Cotynessa gen. nov., type species C. abatinga sp. nov.; in Phlyctaenodini: Ancylodonta apipema sp. nov.; in Neocorini: Marauna gen. nov., type species M. punctatissima sp. nov.; in Oxycoleini: Oxycoleus flavipes sp. nov., all from Bolivia, Santa Cruz; Coscinedes oaxaca sp. nov. from México, Oaxaca; in Elaphidionini: Curtomerus piraiuba sp. nov. from Colombia, Boyacá.
\end{abstract}

KEYWORDS. Cerambycidae, Coleoptera, Neotropical, new taxa, taxonomy.

RESUMO. São descritos e ilustrados os seguintes novos táxons - em Oemini, Methioidina: Kalore gen. nov., espécie-tipo K. asanga sp. nov.; em Methiini: Tessaropa boliviana sp. nov.; em Smodicini: Marupiara gen. nov., espécie-tipo M. castanea sp. nov.; em Ectenessini: Cotynessa gen. nov., espécie-tipo C. abatinga sp. nov.; em Phlyctaenodini: Ancylodonta apipema sp. nov.; em Neocorini: Marauna gen. nov., espécie-tipo M. punctatissima sp. nov., em Oxycoleini: Oxycoleus flavipes sp. nov., todos da Bolívia, Santa Cruz; Coscinedes oaxaca sp. nov. do México, Oaxaca; em Elaphidionini: Curtomerus piraiuba sp. nov. da Colômbia, Boyacá.

PALAVRAS-CHAVE. Cerambycidae, Coleoptera, Neotropical, novos táxons, taxonomia.

O material desta contribuição foi recebido, em sua maior parte, através de James Wappes, San Antonio, Texas (ACMB). De acordo com sua orientação, os holótipos das espécies novas provenientes da Bolívia serão depositados no Museu Noel Kempf Mercado, Santa Cruz (MNKM). Também é utilizado material do Instituto de Investigaciones de Recursos Biológicos "Alexander von Humboldt”, Villa de Leyva, Colômbia (IAHC). Alguns parátipos são retidos para o Museu de Zoologia, Universidade de São Paulo, São Paulo (MZSP).

São descritos táxons em diversas tribos de Cerambycinae com olhos grosseiramente facetados, com exceção de Oemini (Methioidina) e Oxycoleini (olhos finamente facetados). Acrescentamos novos gêneros nas tribos Oemini (Methioidina), Smodicini, Ectenessini, Neocorini; novas espécies são descritas em Methiini, Phlyctaenodini, Elaphidionini e Oxycoleini, tribos que já foram tratadas na obra "Cerambycidae sul-americanos" (MARTins, 1997, 1998, 2002, 2003, 2004, 2005).

\section{OEMINI, METHIOIDINA Kalore gen. nov.}

Etimologia. Kaloré, nome de origem indígena da tribo Kaigangue; $\mathrm{ka}=$ árvore; lo = pintado; re = campo; campo das árvores marcadas.

Espécie-tipo. Kalore asanga sp. nov.

Fronte transversal. Olhos inteiros, finamente facetados; lobos oculares superiores tão distantes entre si quanto o quádruplo da largura de um lobo. Genas com ápice arredondado. Palpos maxilares muito curtos, apenas mais longos que os labiais. Antenas (†) apenas mais longas que o corpo. Escapo alargado para o ápice, curvo no lado inferior e com cerca de metade do comprimento do antenômero III. Pedicelo com cerca de metade do comprimento do escapo. Antenômero III com pêlos em toda a superfície e franja interna de pêlos longos. Antenômero IV com comprimento subigual ao do III. Protórax apenas mais largo do que longo, com constrição basal mais acentuada que a anterior. Lados arredondados. Pronoto com cinco tubérculos: dois látero-anteriores, manifestos e arredondados no topo; um central, longitudinal, que vai quase do ápice à base e mais largo na parte posterior; dois látero-basais. Superfície pronotal glabra e pontuada. Élitros brilhantes, encurtados, atingem a base do urosternito II; lados dos élitros paralelos e deiscentes na sutura. Cavidades coxais anteriores abertas atrás. Processos prosternal e mesosternal laminiformes. Fêmures pedunculados e clavados; ápice dos metafêmures atinge a base do urosternito III. Metatíbias cilíndricas. Metatarsômero I pouco mais longo que II+III.

Discussão. Pela chave para os gêneros de Methioidina (Martins, 1997), Kalore gen. nov. é discriminado no item 5 junto com Methioeme Zajciw, 1963 e Necydalosaurus Tippmann, 1960 pelos élitros reduzidos. Separa-se de Necydalosaurus pelas cavidades procoxais abertas. De Methioeme, difere pelos olhos nãodivididos; pelo escapo curvo; pela presença de tubérculos no pronoto; pelas pernas mais curtas (os ápices dos metafêmures atingem a base do urosternito III); pela presença de processos pro- e mesosternais e pelo aspecto geral brilhante. Em Methioeme, os olhos 
são divididos, o escapo não tem curvatura basal, o pronoto é liso, os processos pro- e mesosternal são ausentes, as pernas são longas (os ápices dos metafêmures atingem o urosternito V) e o aspecto geral é opaco.

\section{Kalore asanga sp. nov. (Fig. 1)}

Etimologia. Tupi, asanga $=$ curto, alusivo ao comprimento dos élitros.

Colorido corporal preto na face dorsal e alaranjado em grande parte da face ventral; élitros alaranjados em parte da superfície. Pronoto com pubescência serícea nas regiões entre os tubérculos. Élitros sem costas, pontuados, menos junto ao ápice. Pêlos ao redor do escutelo (vistos de perfil) amarelados e moderadamente longos. Fêmures alaranjados. Tíbias e tarsos pretos.

Dimensões em mm. Comprimento até o ápice dos élitros, 5,0; comprimento do protórax, 1,0; maior largura do protórax, 1,1; comprimento do élitro, 3,0; largura umeral, 1,5 .

Material-tipo. Holótipo $\&$, BOLÍlVIA, Santa Cruz Amboro ("road above Achira, campo, 5-5800 feet"), 911.X.2004, Wappes \& Morris col. (MNKM).

\section{METHIINI \\ Tessaropa boliviana sp. nov. (Fig. 2)}

Macho. Cabeça, antenas, mesonoto, escutelo, metade apical dos élitros, meso- e metasterno, coxas, abdômen, mais da metade apical das tíbias e tarsos, pretos. Gula, protórax, fêmures e base dos élitros, amarelo-alaranjados. Cabeça densamente pontuada. Olhos divididos. Antenômeros basais com franja interna de pêlos abundantes. Lados do protórax com finas rugas. Regiões anterior e posterior do pronoto com rugas transversais finíssimas. Élitros com costas indicadas. Ponta do processo prosternal visível entre as procoxas.

Dimensões em mm. Comprimento dos tubérculos anteníferos ao ápice dos élitros, 4,4; comprimento do protórax, 1,1; maior largura do protórax, 0,9; comprimento do élitro, 2,5; largura umeral, 1,2.

Material-tipo. Holótipo đ゙, BOLÍVIA, Santa Cruz: Amboro ("road above Achira, campo, 5-5800 feet"), 911.X.2004, Morris \& Wappes col. (MNKM)

Discussão. Tessaropa boliviana sp. nov. assemelha-se a $T$. carioca Martins, 1981, que está figurada em Martins \& GaliLEO (1997:177, fig. 154), principalmente pelos olhos divididos, pela franja de pêlos densos nos flagelômeros basais, pelo mesonoto sem sulco e pelo ápice do processo prosternal visível entre as procoxas. Tessaropa boliviana difere de T. carioca pela cabeça, lado anterior do escapo, mesonoto e escutelo pretos e pelo protórax estriado. Em T. carioca, essas regiões são alaranjadas e o protórax não tem rugosidades. Entretanto, em que pese a distribuição diferente, é possível que $T$. boliviana sp. nov. venha a constituir uma forma extrema de T. carioca.

\section{SMODICINI \\ Marupiara gen. nov.}

Etimologia. Tupi, marupiara $=$ feliz, felizardo.

Espécie-tipo. Marupiara castanea sp. nov.

Cabeça prognata. Lobos oculares superiores tão distantes entre si quanto mais do que o dobro da largura de um lobo. Tubérculos anteníferos aguçados. Antenas dos machos ultrapassam o ápice elitral por um artículo; escapo, antenômeros III e IV com comprimentos subiguais; pedicelo tão longo quanto metade do antenômero III. Nas fêmeas, as antenas não atingem a extremidade dos élitros; pedicelo com um terço do comprimento do antenômero III e este pouco mais longo que o IV. Protórax pouco mais longo do que largo, com a constrição basal mais acentuada que a anterior. Dois terços posteriores das partes laterais do protórax e do prosterno com pontuação sexual. Pronoto pontuado. Processo prosternal laminiforme entre as coxas e algo alargado para o ápice. Processo mesosternal estreito, com lados paralelos, largamente entalhado no ápice. Élitros aplanados e não-expandidos. Fêmures fusiformes; os dos machos mais engrossados do que os das fêmeas. Lobos do metatarsômero III alargados para o ápice.

Discussão. Marupiara gen. nov. difere de Nesosmodicum Martins, 1971 pelo antenômero III com o dobro do comprimento do pedicelo e do mesmo comprimento que o antenômero IV; pelo processo prosternal laminiforme entre as procoxas; pelos élitros não-expandidos lateralmente e pelos lobos do metatarsômero III mais largos. Em Nesosmodicum, o antenômero III é apenas mais longo que o pedicelo e tão longo quanto metade do antenômero IV; o processo prosternal é espatulado e os élitros são um pouco expandidos no quarto apical.

Distingue-se de Smodicum Haldeman, 1847 pelos processos pro- e mesosternal mais estreitos; pelas antenas mais longas, principalmente nos machos; pelo pedicelo tão longo quanto a metade do comprimento do antenômero III. Em Smodicum, os processos pro- e mesosternal têm, respectivamente, metade e dois terços de uma cavidade coxal; as antenas dos machos, no máximo, atingem os ápices dos élitros e o pedicelo tem menos da metade do antenômero III.

\section{Marupiara castanea sp. nov. (Fig. 3)}

Colorido geral castanho-avermelhado; cabeça, região anterior do pronoto e ápices dos antenômeros pouco mais escuros. Todo corpo com setas longas. Pontuação evidente na cabeça e no pronoto. Élitros com pubescência muito esparsa e aspecto brilhante.

Dimensões em $\mathrm{mm}$, respectivamente $\sigma / \%$. Comprimento total, 11,7/11,6; comprimento do protórax, 2,6/2,1; maior largura do protórax, 2,2/2,1; comprimento do élitro, 7,8/8,6; largura umeral, 2,6/2,5. Antena: escapo, 1,1/1,0; pedicelo, 0,5/0,5; antenômero III, 1,1/1,0, antenômero IV, 1,1/1,0. 
Material-tipo. Holótipo $\circlearrowleft$, BOLÍVIA, Santa Cruz: Amboro ("road above Achira, campo, 5-5800 feet"), 911.X.2004, Wappes \& Morris col. (MNKM); parátipo \&, mesmos dados do holótipo (ACMB).

\section{ECTENESSINI \\ Cotynessa gen. nov.}

Etimologia. Combinação das palavras “coty”, tupi, = ao lado de, e parte do nome do gênero-tipo da tribo, Ectenessa.

\section{Espécie-tipo, Cotynessa abatinga sp. nov.}

Todo o corpo provido de pêlos brancos e rijos. Palpos maxilares pouco mais longos que os labiais. Lobos oculares superiores com quatro fileiras de omatídios, tão distantes entre si quanto o dobro da largura de um lobo. Antenas com onze artículos, as dos machos atingem as pontas dos élitros a partir da extremidade do antenômero VII. Escapo ligeiramente engrossado para o ápice, com metade do comprimento do antenômero III; este finamente carenado, apenas mais longo do que o IV. Protórax mais longo do que largo, com lados arredondados e constrição basal mais acentuada que a apical. Pronoto com gibosidades. Partes laterais do protórax com pontuação sexual. Processo prosternal estreitado entre as procoxas (cerca de um sétimo da largura de uma procoxa) e inciso na extremidade. Processo mesosternal quase tão largo quanto uma mesocoxa; ápice não-entalhado. Élitros planos, sem costas, com extremidade obliquamente truncada e desarmada. Protrocanteres dos machos sem modificações. Profêmures fortemente dilatados, sem quilha dorsal. Meso- e metafêmures pedunculados e clavados. Metatíbias carenadas. Metatarsômero I mais longo que o dobro do II+III.

Discussão. Na chave para gêneros de Ectenessini (MARTins, 1998:86), Cotynessa gen. nov., por apresentar processo mesosternal largo, truncado e sem incisão apical, é discriminado com três gêneros: Lissoeme Martins, Chemsak \& Linsley, 1966, Acanthonessa Napp \& Martins, 1982 e Tricheurymerus Zajciw, 1961. Difere de Lissoeme pelo protórax 1,1 vezes mais longo que largo, pelo pronoto com gibosidades, pelas metatíbias carenadas e pela pilosidade branca, rija, em todo o corpo e apêndices. Em Lissoeme, o protórax é 1,4 a 1,5 vezes mais longo que largo; o pronoto não tem gibosidades ou depressões, as metatíbias não são carenadas e a pilosidade corporal é pouco notável, especialmente na cabeça e no tórax.

A pilosidade corporal branca e os ápices dos élitros desarmados distinguem Cotynessa gen. nov. de Acanthonessa e Tricheurymerus.

\section{Cotynessa abatinga sp. nov. (Fig. 4)}

Etimologia. Tupi, aba = cabelo; tinga = branco; alusivo à pubescência de escutelo.

Colorido geral castanho-avermelhado, ligeiramente mais escuro nos élitros. Fronte e vértice com pêlos longos e brancos. Occipício pontuado e brilhante. Pronoto pontuado com quatro elevações lisas: duas arredondadas látero-anteriores e duas alongadas, longitudinais, uma de cada lado da base. Escutelo com pubescência branca. Em cada élitro, mancha oval, dorsal no terço anterior e faixa branca que se inicia perto do meio, junto à sutura, afasta-se ligeiramente até o terço apical, onde volta-se para frente em curta extensão. Pontuação da metade anterior dos élitros moderada. Pêlos elitrais abundantes, ligeiramente mais longos que os demais. Pêlos da face ventral abundantes e mais finos que os restantes.

Dimensões em mm, holótipo $₫$. Comprimento total, 12,0; comprimento do protórax, 2,6; maior largura do protórax, 2,3; comprimento do élitro, 8,3; largura umeral, 2,7 .

Material-tipo. Holótipo đ, BOLÍVIA, Santa Cruz: Amboro ("road above Achira, campo, 5-5800 feet"), 911.X.2004, Morris \& Wappes col. (MNKM).

\section{PHLYCTAENODINI Ancylodonta apipema sp. nov. (Fig. 5)}

Etimologia. Tupi, apipema = alto da serra, alusivo à altitude da localidade onde foi coligida.

Colorido geral avermelhado. Antenas e pernas ligeiramente mais claras. Fronte e vértice densamente pontuados. Antenas da fêmea quase atingem o ápice dos élitros. Antenômero XI mais longo que o X. Protórax com constrição anterior mais acentuada que a basal; partes laterais com espinho curvo para cima. Pronoto densamente pontuado, menos no topo dos tubérculos anteriores. Base dos élitros com alguns pontos ásperos; toda a superfície elitral com pêlos curtos e espaçados. Extremidades elitrais levemente emarginadas, com projeção no lado externo. Lados do metasterno e metepimeros fina- e densamente pontuados.

Dimensões em mm, holótipo \&. Comprimento total, 11,9; comprimento do protórax, 1,7; maior largura do protórax, 2,2; comprimento do élitro, 9,2; largura umeral, 2,7 .

Material-tipo. Holótipo $\&$, BOLÍVIA, Santa Cruz: Amboro ("road above Achira, campo, 5-5800 feet"), 911.X.2004, Wappes \& Morris col. (MNKM).

Discussão. Ancylodonta apipema sp. nov. assemelha-se a A. phlyctaenoides (Lacordaire, 1869) pelo ápice dos élitros emarginado e com projeção no lado externo. Difere pelo antenômero III subigual em comprimento ao IV; protórax com pontuação mais densa e compacta; base dos élitros com pontos ásperos e presença de pêlos curtos em toda a superfície elitral. Em A. phlyctaenoides, o antenômero III tem cerca da metade do comprimento do IV; o pronoto tem pontuação mais esparsa; a base dos élitros não tem pontos ásperos e os élitros são glabros.

A presença de pontos ásperos na base dos élitros também ocorre em A. tristis Blanchard, 1851 e A. almeidai (Mendes, 1946); aquela com extremidade dos élitros desarmadas e arredondadas em conjunto, esta com extremidades cortadas em curva com espinho externo e projetadas no ângulo sutural. Além disso, os élitros de $A$. 
almeidai são desprovidos de pêlos curtos e os pontos da base dos élitros são extremamente ásperos e muito numerosos.

\section{NEOCORINI Marauna gen. nov.}

Etimologia. Tupi, maraúna = espécie de fantasma, assombração.

\section{Espécie-tipo. Marauna punctatissima sp. nov.}

Cabeça no nível dos lobos oculares inferiores mais larga que o protórax. Fronte oblíqua. Tubérculos anteníferos distantes entre si, com ápice agudo. Olhos grosseiramente facetados. Lobos oculares superiores com quatro fileiras de omatídios, tão afastados entre si quanto 2,5 vezes a largura de um lobo. Palpos maxilares mais longos que os palpos labiais; último artículo dos palpos labiais e maxilares cilindriformes. Antenas ( $\sigma^{\prime}$ mais longas que o corpo. Escapo gradualmente engrossado para o ápice, mais longo que o antenômero III. Antenômero III mais curto que o IV. Lado interno dos antenômeros sem pêlos. Protórax subcilíndrico, mais longo do que largo; os lados levemente projetados no nível do terço posterior. Pronoto com quatro gibosidades muito discretas, duas anteriores e duas basais. Pontuação pronotal grossa e densa. Élitros densamente pontuados em toda a superfície; extremidades arredondadas. Processo prosternal estreito entre as procoxas. Processo mesosternal estreito, com menos da metade da largura de uma mesocoxa, inciso no ápice. Esternos torácicos e urosternitos densamente pontuados. Fêmures pedunculados e clavados. Metatarsômero I tão longo quanto o II+III.

Discussão. Marauna gen. nov. assemelha-se a Fregolia Gounelle, 1911; difere pelo escapo engrossado para o ápice; pelo protórax sensivelmente mais longo que largo, sem tubérculos pronunciados no dorso; pelos fêmures pedunculados e clavados e pelo processo mesosternal com menos da metade da largura de uma mesocoxa. Em Fregolia: escapo subcilíndrico, protórax pouco mais longo do que largo, com quatro gibosidades notáveis no pronoto, fêmures pedunculados e com clava mais esbelta e processo mesosternal mais largo que a metade de uma mesocoxa.

\section{Marauna punctatissima sp. nov.} (Fig. 6)

Colorido geral vermelho-acastanhado; pedicelo e flagelômeros com ápices pretos, bases dos fêmures e das tíbias e tarsos amarelados. Todo o corpo, menos antenas e pernas, densa- e profundamente pontuados. Dorso do sexto apical dos élitros com alguma pubescência que não chega a constituir faixa.

Dimensões em mm, holótipo $₫$. Comprimento total, 6,3; comprimento do protórax, 1,2; maior largura do protórax, 0,8; comprimento do élitro, 4,5; largura umeral, 1,2 .
Material-tipo. Holótipo ơ, BOLÍVIA, Santa Cruz: Amboro ("road above Achira, campo, 5-5800 feet"), 911.X.2004, Wappes \& Morris col. (MNKM). Parátipo ơ, com os mesmos dados do holótipo (ACMB).

\section{Coscinedes oaxaca sp. nov. (Fig. 7)}

Cabeça preta, glabra, forte- e densamente pontuada. Olhos sub-reniformes, com os lobos inferiores salientes; lobos superiores ausentes. Escapo, pedicelo, antenômeros II-IV avermelhados; antenômeros V-XI avermelhados na base e escurecidos para o ápice. Antenas ( $\left.\sigma^{\prime}\right)$ mais curtas que o corpo. Escapo finamente pontuado, tão longo quanto o antenômero III; este apenas mais longo que o antenômero IV; flagelômeros apicais levemente projetados no ângulo externo. Protórax forte e densamente pontuado, mais longo que largo, com constrição basal bem acentuada; lados do protórax arredondados. Pronoto e prosterno pretos; partes laterais e constrição basal do protórax avermelhadas. Meso- e metasterno avermelhados, densa- e fortemente pontuados. Élitros com pouco mais que o terço basal vermelho-alaranjado e pretos no restante; friso sutural vermelho-alaranjado; densamente pontuados em toda a superfície; extremidades arredondadas. Fêmures pretos com pedúnculo avermelhado, sem pontos notáveis. Tíbias e tarsos avermelhados. Urosternitos pretos, o I e o II forte- e densamente pontuados.

Dimensões em mm, holótipo $\% /$ parátipo $\sigma$. Comprimento total, 6,0-6,4; comprimento do protórax, 1,31,4; maior largura do protórax, 1,0-1,1; comprimento do élitro, 4,1-4,3; largura umeral, 1,1-1,2.

Material-tipo. Holótipo O', MÉXICO, Oaxaca: $7 \mathrm{~km}$ NNW Diaz Ordaz (2.200 m), 11.VII.1992, C. L. Bellamy col. (ACMB). Parátipo ơ, ditto, N of HWY 190, $7 \mathrm{~km} \mathrm{~N}$. Diaz Ordaz, 17.VII.1992, G. H. Nelson \& D. S. Verity col. "on Cassia sp." (MZSP).

Discussão. O gênero Coscinedes Bates, 1885 só era conhecido pela espécie-tipo, C. gracilis Bates, 1885. Coscinedes oaxaca sp. nov. difere de $C$. gracilis pelo colorido e aspecto geral mais esbelto. A relação entre o comprimento dos élitros e a largura umeral em $C$. gracilis é 2,0-2,9 vezes, ao passo que em C. oaxaca sp. nov. é 3,73,9 vezes.

\section{ELAPHIDIONINI Curtomerus piraiuba sp. nov. (Fig. 8)}

Etimologia. Tupi, piraîuba $=$ dourado, alusivo à pilosidade do pronoto.

Colorido geral avermelhado. Cabeça com pubescência amarelo-dourada esparsa. Fronte lisa. Tubérculos anteníferos projetados, com ápice arredondado. Escapo com rugosidades. Antenas (o') não atingem a ponta dos élitros. Pronoto com áreas de pontuação sexual látero-anteriores que não estão muito próximas no centro; de cada um dos lados da base, com bossa coberta por pilosidade amarelo-dourada. Partes laterais do protórax com pontuação sexual em toda a 

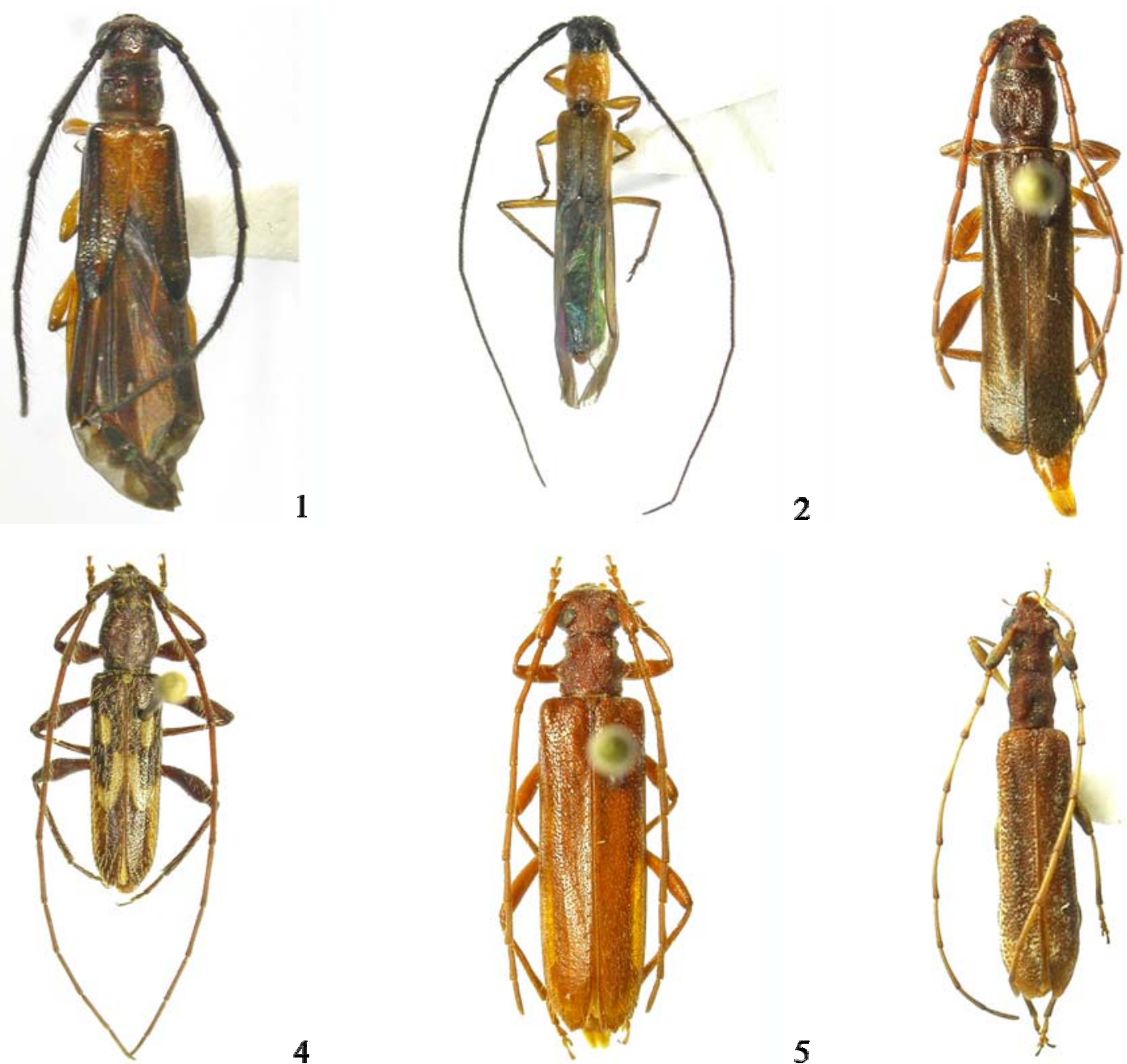

1

2

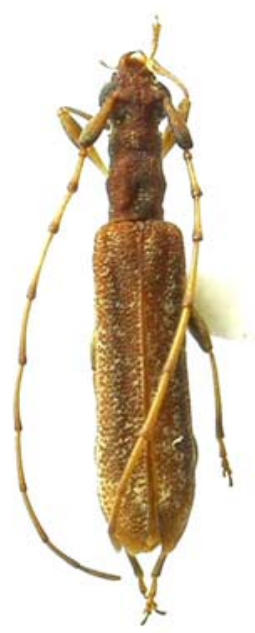

6
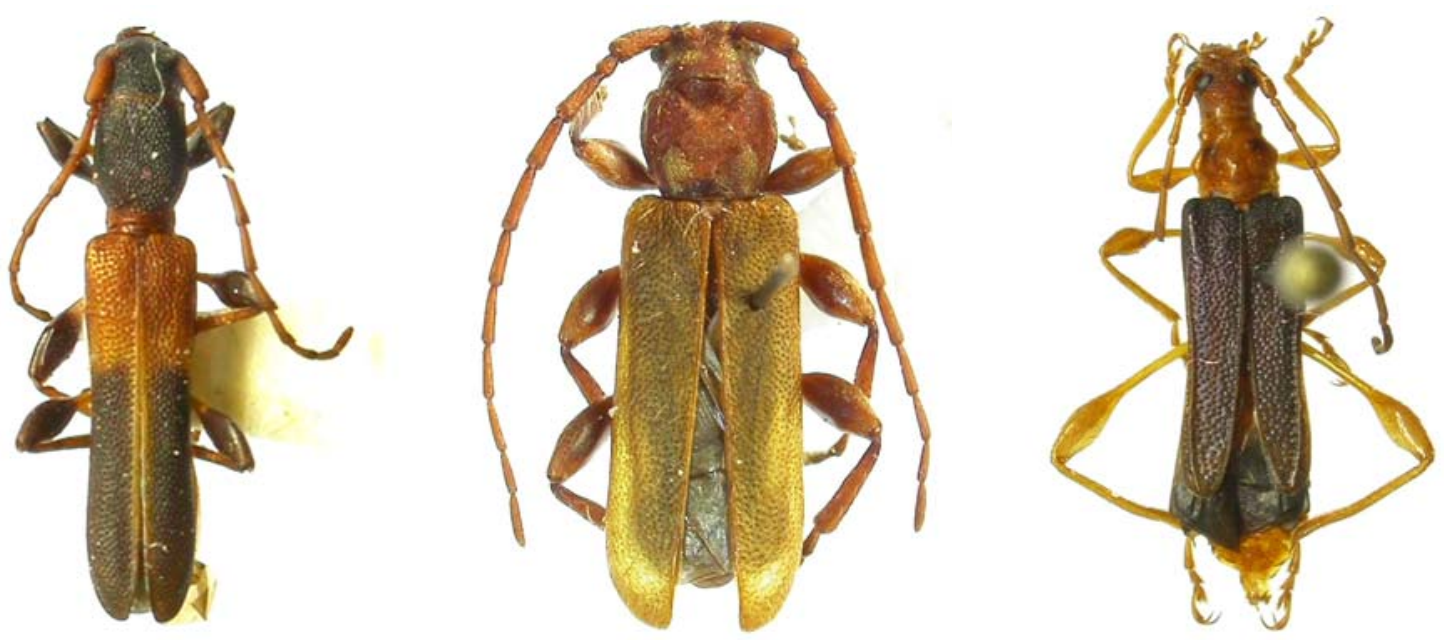

7

8

Figs. 1-9. Habitus. 1, Kalore asanga sp. nov., holótipo \&, comprimento dos tubérculos anteníferos ao ápice dos élitros, 5,0 mm; 2, Tessaropa boliviana sp. nov., holótipo o", comprimento dos tubérculos anteníferos ao ápice dos élitros, 4,4 mm; 3, Marupiara

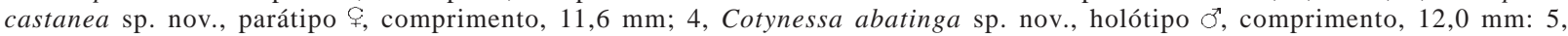
Ancylodonta apipema sp. nov., holótipo \&, comprimento, 11,9 mm; 6, Marauna punctatissima sp. nov., holótipo §', comprimento, $6,3 \mathrm{~mm} ; 7$, Coscinedes oaxaca sp. nov., holótipo $\sigma$, comprimento, 6,4 mm; 8, Curtomerus piraiuba sp. nov., holótipo $\sigma$, comprimento,

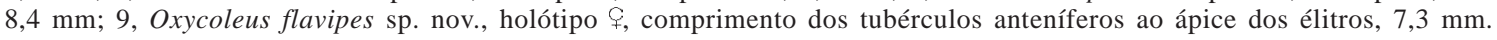


superfície. Prosterno sem pontuação sexual, intumescido, com tegumento estriado. Processo prosternal estreito e acuminado para o ápice. Élitros com cerdas esparsas, pontuados e microesculturados.

Dimensões em mm, o. Comprimento total, 7,4-8,4; comprimento do protórax, 1,4-1,6; maior largura do protórax, 1,1-1,9; comprimento do élitro, 5,3-6,0; largura umeral, 2,0-2,4.

Material-tipo. Holótipo ơ, COLÔMBIA, Boyacá: SFF Iguaque (Lagunillas, $5^{\circ} 25^{\prime} \mathrm{N}, 7^{\circ} 27^{\prime} \mathrm{W}, 3.380 \mathrm{~m}$ ), 9-24.II.2001, P. Reyes col., Malaise, M 1272 (IAHC). Parátipo ơ, COLÔMBIA, Boyacá: SFF Iguaque (Cabaña Marmaramos, m4, $5^{\circ} 25^{\prime} \mathrm{N}$ $\left.73^{\circ} 27^{\prime} \mathrm{W}, 2.855 \mathrm{~m}\right), 23 . \mathrm{V}-8 . V I .2000$, P. Reyes col., Malaise, M. 149 (MZSP)

Discussão. Pela chave para as espécies sulamericanas de Curtomerus (MARTINs, 2005), C. piraiuba sp. nov. é discriminada com C. brunneus (Kirch, 1889) do Equador e C. purus Martins, 1964 da Bolívia. Separase de ambas pela presença de pilosidade amarelo-dourada nos lados da base do pronoto. Além disso, em $C$. brunneus a extremidade dos metafêmures dos machos atinge os ápices dos élitros.

\section{OXYCOLEINI \\ Oxycoleus flavipes sp. nov. (Fig. 9)}

Cabeça, escapo, pedicelo, protórax, escutelo, pernas e face ventral do corpo, alaranjados. Antenômeros III-VI alaranjados com extremidades escurecidas; antenômeros VII-XI inteiramente escuros. Pronoto com duas manchas castanho-escuras na metade anterior. Élitros preto-violáceos com ápice castanho-alaranjado. Fronte esparsamente pontuada. Flagelômeros basais cilíndricos. Pronoto com gibosidades como habitual no gênero. Élitros deiscentes do meio em diante com carena lateral do quinto basal até o ápice; a ponta alcança a margem posterior do urosternito II; ápice arredondado. Ponta dos metafêmures não atinge o ápice do abdômen.

Dimensões em mm, holótipo . Comprimento total (até o ápice dos élitros), 7,3; comprimento do protórax, 1,3; maior largura do protórax, 1,5; comprimento do élitro, 4,9; largura umeral, 2,0.

Material-tipo. Holótipo $\subsetneq$, BOLÍVIA, Santa Cruz: Achira (4-6 km N, 5400-5800 pés), 20.XI.2003, Wappes, Morris \& Nearns col. (MNKM).

Discussão. Oxycoleus flavipes sp. nov. assemelhase a O. laetus Júlio, 1997 pelo colorido geral; difere pelas pernas, face ventral e antenas amareladas; élitros sem reflexo azulado e com carena lateral manifesta do quinto basal até quase o ápice. Em O. laetus, as antenas, pernas e face ventral são pretas, os élitros têm reflexo azulado e não têm carenas. Separa-se de $O$. cyaneus Martins \& Galileo, 2005, que também ocorre na Bolívia, pelos flagelômeros basais, pernas e urosternitos alaranjados e pelos élitros sem brilho metálico azul. Em O. cyaneus, as antenas, a clava dos fêmures, metade basal das pró- e mesotíbias, metatíbias, metatarsos e urosternitos são pretos; os élitros são azul-metálicos e brilhantes.

Agradecimentos. A James Wappes (ACMB), pela remessa de material para estudo e a Rafael Santos de Araujo, Museu de Ciências Naturais, Fundação Zoobotânica do Rio Grande do Sul, pela execução das fotografias.

\section{REFERÊNCIAS BIBLIOGRÁFICAS}

Martins, U. R. org. 1997. Cerambycidae sul-americanos (Coleoptera). São Paulo, Sociedade Brasileira de Entomologia. v. 1, vi+217p.

1998. Cerambycidae sul-americanos (Coleoptera). São Paulo, Sociedade Brasileira de Entomologia. v. 2, vi+195p. 2002. Cerambycidae sul-americanos (Coleoptera). São Paulo, Sociedade Brasileira de Entomologia. v. 4, iv +265 p. 2003. Cerambycidae sul-americanos (Coleoptera). São Paulo, Sociedade Brasileira de Entomologia. v. 6, vii $+232 p$. 2004. Cerambycidae sul-americanos (Coleoptera). São Paulo, Editora da Universidade de São Paulo. v. 5, vi+284p. 2005. Cerambycidae sul-americanos (Coleoptera). São Paulo, Sociedade Brasileira de Entomologia. v. 7, ii $+394 p$.

Martins, U. R. \& Galileo, M. H. M. 1997. Tribo Methiini. In: Martins, U. R. org. Cerambycidae sul-americanos (Coleoptera). São Paulo, Sociedade Brasileira de Entomologia. v. 1, p.159-179.

Recebido em novembro de 2005. Aceito em janeiro de 2006. ISSN 0073-4721

Artigo disponível em: www.scielo.br/isz 